\title{
Pediatric myelodysplastic/myeloproliferative neoplasms and related diseases
}

\author{
Karthik A. Ganapathi ${ }^{1}$ - Kristian T. Schafernak ${ }^{2}$ - V. Koneti Rao ${ }^{3}$. \\ Katherine R. Calvo ${ }^{4}$ (i)
}

Received: 10 February 2015 / Accepted: 8 June 2015 /Published online: 25 June 2015

(C) Springer-Verlag Berlin Heidelberg (Outside the USA) 2015

\begin{abstract}
Myelodysplastic/myeloproliferative neoplasms (MDS/MPN) are clonal hematopoietic disorders with myeloproliferative features, varying degrees of dysplasia and cytopenias, and increased propensity for progression to acute myeloid leukemia (AML). MDS/MPN are uncommon in the pediatric age group, and best exemplified by Juvenile myelomonocytic leukemia (JMML), a rare but aggressive leukemia of early childhood. Remarkable progress has been made in understanding the genetic basis of JMML leading to improved diagnostic criteria and better management. It is now understood that JMML is associated with somatic or germ line mutations in NF1, NRAS, KRAS, PTPN11, and CBL in greater than $90 \%$ of cases with the common downstream mechanism being uncontrolled activation of the RAS/MAPK pathway. More recently, KRAS and NRAS mutations have also been identified in RAS-associated autoimmune leukoproliferative disorder (RALD), which shares some clinical, hematopathological, and genetic features with JMML, but has an indolent clinical course. Hematopoietic stem cell transplant (HSCT) is currently the only curative therapy for
\end{abstract}

Katherine R. Calvo

calvok@mail.nih.gov

1 Department of Pathology and Cell Biology, Division of Hematopathology, Columbia University Medical Center, New York, NY, USA

2 Department of Pathology and Laboratory Medicine, Ann \& Robert H. Lurie Children's Hospital of Chicago, Chicago, IL, USA

3 Laboratory of Immunology, National Institute of Allergy and Infectious Diseases (NIAID), National Institutes of Health (NIH), Bethesda, MD, USA

4 Hematology Section, Department of Laboratory Medicine, National Institutes of Health Clinical Center, 10 Center Dr, Bldg 10/2C306, Bethesda, MD 20892-1508, USA
JMML, although newer therapeutic agents are currently in clinical trials. This review will focus primarily on the current clinical features, diagnostic criteria, pathologic features, and therapy of JMML and provide a brief description of RALD.

Keywords Myelodysplastic/myeloproliferative neoplasms (MDS/MPN) · Juvenile myelomonocytic leukemia (JMML) · RAS-associated autoimmune leukoproliferative disorder (RALD)

\section{Introduction}

Myelodysplastic/myeloproliferative neoplasms (MDS/MPN) are clonal hematopoietic disorders with overlapping features of myelodysplasia and myeloproliferation. The 2008 WHO classification of MDS/MPN includes three defined disorders: chronic myelomonocytic leukemia (CMML), juvenile myelomonocytic leukemia (JMML), and atypical chronic myeloid leukemia, BCR-ABL1 negative (aCML). A fourth category, MDS/MPN-unclassifiable (MDS/MPN, U) is reserved for myeloid neoplasms not meeting diagnostic criteria for the other three [1]. CMML and aCML are typically disorders of adulthood while JMML, as the name implies is seen in children. Myeloproliferation in MDS/MPN is most often a result of aberrant RAS/MAPK signaling with the vast majority of JMML patients exhibiting mutations in NF1, PTPN11, CBL, $N R A S, K R A S$, and a subset of CMML and aCML patients showing NRAS mutations [2, 3]. The identification of RAS/ MAPK pathway protein mutations in patients with rare genetic disorders has also provided insights into leukemogenesis, biomarkers, and therapeutic targets [2]. These studies have also demonstrated the invaluable role of astute clinical observations combined with powerful genomic analysis in understanding the biology of disease. 


\section{Juvenile myelomonocytic leukemia}

\section{Epidemiology}

JMML is a rare, aggressive myeloproliferative neoplasm that occurs exclusively in children with an approximate annual incidence of 1.2 cases per million from infancy to early adolescence, but the majority of cases are diagnosed in children $<3$ years with boys affected twice as often as girls. A fraction of cases occurs in children with neurofibromatosis type I (NF1) [1].

\section{Clinical and laboratory features}

JMML patients usually present with non-specific constitutional symptoms including fever, cough, tachypnea, and evidence of infection. Hepatosplenomegaly is present, although in rare cases, the spleen is not enlarged at diagnosis. Lymphadenopathy or enlarged tonsils is identified in some cases. Skin lesions are common, including eczematous patches, erythematous papules, and juvenile xanthogranulomas. Café-au-lait spots are noted in children with NF1.

Leukocytosis, anemia, and thrombocytopenia are characteristic of JMML. The median WBC count ranges from 25 to $33 \times 10^{9} / \mathrm{L}$ but can occasionally exceed $100 \times 10^{9} / \mathrm{L}$ secondary to neutrophilia and monocytosis $[4,5]$. Absolute monocytosis, $>1 \times 10^{9} / \mathrm{L}$ is required for diagnosis. However, unlike chronic myelomonocytic leukemia (CMML), persistent monocytosis, defined as greater than 3 months duration, is not required for the diagnosis of JMML. Of note, an absolute monocyte count of $1 \times 10^{9} / \mathrm{L}$ or greater can also be seen in healthy infants. The peripheral blood smear often shows left-shifted myeloid cells and monocytes, but blasts are $<2 \%$ in approximately half of cases (Fig. 1a). Overt morphologic dysplasia may be lacking.
Anemia is usually normocytic and circulating nucleated red cells can be seen. Thrombocytopenia can range from moderate to life threatening [4].

Most JMML patients have abnormally high hemoglobin $\mathrm{F}$ $(\mathrm{Hb} \mathrm{F})$ levels. Elevated $\mathrm{Hb} F$ levels are not specific for JMML as high $\mathrm{Hb} \mathrm{F}$ levels can also be seen in other settings of stressed erythropoiesis in children (e.g., MDS, sickle cell disease, hereditary persistence of fetal hemoglobin, and bone marrow failure syndromes). Additionally, interpreting $\mathrm{Hb} F$ levels in young children can be challenging due to widely fluctuating levels seen in infancy. A subset of JMML has immune abnormalities including polyclonal hyperglobulinemia and circulating autoantibodies. Myeloid progenitor cells from JMML patients show selective hypersensitivity to granulocytemacrophage colony-stimulating factor (GM-CSF), a feature that is used as a diagnostic test [6]. In cases of suspected JMML, infection with EBV, CMV, and HHV-6 should be excluded in addition to any other infectious process that may present with monocytosis and features overlapping with JMML. Autoimmune diseases, including rheumatoid arthritis and systemic lupus erythematosus can also present with monocytosis and rarely thrombocytopenia and should be considered in the differential diagnosis.

\section{Histologic features}

The bone marrow is hypercellular with varying degrees of myeloid hyperplasia, left-shifted maturation with subtle or absent dysplastic features; however, blasts, by definition, are less than $20 \%$. Monocytosis and dysgranulopoiesis are often not as prominent in the marrow, as in peripheral blood. Erythroid maturation may appear megaloblastic and megakaryocytes are reduced $[4,7]$ (Fig. 1b-c).

Fig. 1 a-c JMML-like disorder in an 11-week-old boy with mildly dysmorphic facies, short broad neck, widely spaced nipples, and very enlarged and firm spleen, ultimately found to have Noonan syndrome and a PTPN11 c.218C $>$ T (p.Thr73Ile) mutation. The peripheral blood smear (a) was remarkable for a leukocytosis of nearly $50 \times 10^{9} / \mathrm{L}$ and $36 \times 10^{9} / \mathrm{L}$ platelets. Neutrophils were shifted to immaturity and rare blasts were present, along with almost $9 \times$ $10^{9} / \mathrm{L}$ monocytes. The trephine biopsy (b) showed a virtually $100 \%$ cellular marrow [normal for age would be $80-90 \%$ ] with myeloid hyperplasia. The aspirate smears (c) similarly demonstrated myeloid hyperplasia, and blasts were mildly increased at $9 \%$. d JMML in a 7-year-old girl with NF1. Initial presentation of JMML was gradually increasing leukocytosis with absolute monocytosis, rare circulating blasts, thrombocytopenia, and hepatosplenomegaly. Hemoglobin $\mathrm{F}$ was elevated for age at $15.8 \%$ [normal $<2 \%$ ]. The bone marrow aspirate (shown) revealed $15 \%$ blasts, $8 \%$ basophils, and $2 \%$ monocytes. An abnormality of chromosome 5 was seen on conventional cytogenetic analysis. She underwent allogeneic stem cell transplantation. Bone marrow examination at day +100 showed similar findings, confirming relapse which had been suspected on the basis of falling chimerism. e-f Splenectomy specimen from 22-month-old boy with JMML, status-post cord blood transplant, with primary graft failure. The spleen was markedly enlarged and the red pulp diffusely infiltrated by a myeloid/monocytic proliferation (e) Myeloperoxidase immunostain highlighting the myeloid infiltrate is depicted in (f). $\mathbf{g}$-i MDS/MPN, U with increased blasts in a 17-year-old boy with RANBP2-ALK fusion. The peripheral blood (g) showed a marked leukocytosis of $114 \times 10^{9} / \mathrm{L}$ but more modest anemia and thrombocytopenia. Neutrophils were dysplastic and shifted to immaturity with $5 \%$ circulating blasts. Thirty-one percent monocytes were present. The trephine biopsy (h) demonstrated a virtually $100 \%$ cellular marrow [normal for age would be $40-60 \%$ ]. The aspirate smears (i) had increased "blast equivalents" (mainly promonocytes) accompanied by $65 \%$ maturing/mature granulocytes and $12-13 \%$ mature-appearing monocytes but was insufficient for a diagnosis of AML. Of note, the patient had no history of prior therapy, as is typically seen in pediatric CMML. The patient's age was not typical for JMML or adult-type CMML, and the case was considered most consistent with MDS/MPN, U. j-l RALD in an 8-year-old girl with splenomegaly, lymphadenopathy, leukocytosis with absolute monocytosis (1.4 $\times$ $10^{9} / \mathrm{L}$ ), lymphocytosis, and thrombocytopenia. Onset of symptoms began at the age of 4 years, and a somatic mutation in $K R A S \mathrm{c} .38 \mathrm{G}>\mathrm{A}$ (p.Gly13Asp) was subsequently identified. The patient has hypergammaglobulinemia and is positive for lupus anticoagulant, anti-nuclear antibodies, and is DAT positive. Peripheral smear shows vacuolated monocytes (j) with a significant subset of CD16+ monocytes by flow cytometry (not shown). Bone marrow core biopsy shows a hypercellular marrow (k). Aspirate smear is cellular with evidence of granulocytic hyperplasia, mild-to-moderate left shift in myeloid maturation, less than $5 \%$ blasts, and a normal karyotype on cytogenetic analysis (l) 


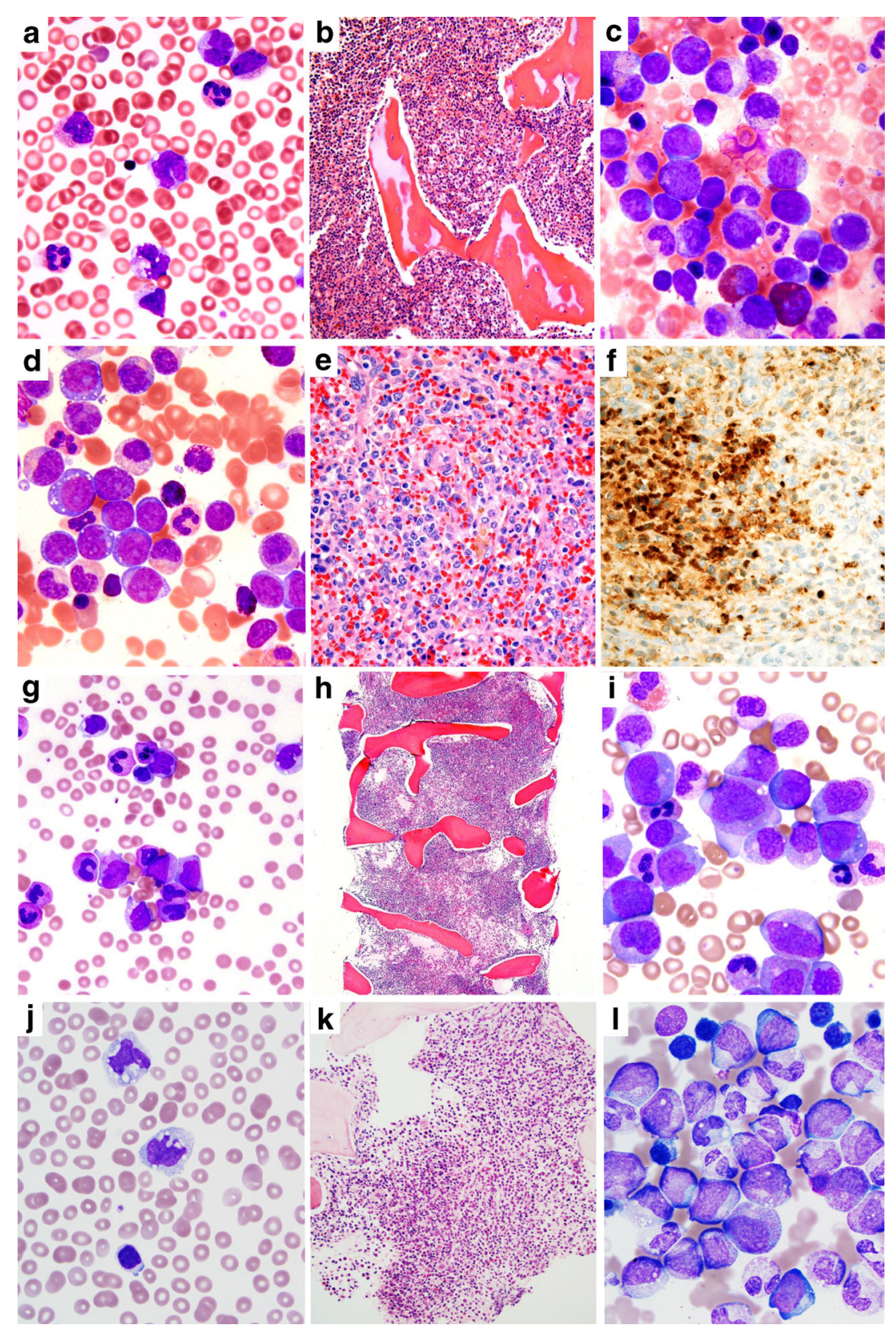

Extramedullary involvement is common. Hepatic leukemic infiltrates are seen in a periportal and sinusoidal distribution. Splenic infiltrates expand the red pulp leading to compression of the white pulp (Fig. 1e-f). Tonsillar and cutaneous infiltrates can also be identified.

\section{Cytogenetics}

Monosomy 7 is the most common cytogenetic abnormality, seen in approximately $25 \%$ of JMML patients. Other abnormalities are seen in $10 \%$ of cases and $65 \%$ have normal cytogenetics $[4,5]$.

\section{Genetics}

It is now known that uncontrolled activation of the RAS/ MAPK pathway plays a central role in the pathogenesis of JMML. Approximately $90 \%$ of JMML patients harbor mutually exclusive mutations in one of five genes-NF1, PTPN11, $N R A S, K R A S$, and $C B L$ [2].

The observation that patients with NF1 had a higher incidence of JMML led to the discovery that NF1 is a tumor suppressor gene that functions by inhibiting the Ras signaling pathway [8]. Mutations in NF1 account for $10-15 \%$ of JMML cases. Bone marrow analysis of NF1 patients with JMML has shown inactivation of the $N F 1$ gene locus by either 
uniparental disomy (UPD) or compound heterozygous mutations, which are critical events in leukemogenesis [9, 10]. JMML associated with NF1 is typically fatal unless treated with hematopoietic stem cell transplantation (HSCT).

Noonan syndrome (NS) is developmental disorder, which shares some clinical features with NF1, including the increased incidence of JMML and JMML-like transient myeloid proliferations [11-13]. The transient myeloid proliferation (TMP) associated with NS is seen in early infancy and is non-clonal unlike JMML. Most of these patients have spontaneous resolution of their symptoms over a span of months. However, approximately $10 \%$ of patients with NS/TMP acquire a secondary cytogenetic abnormality and progress to JMML. Germ line PTPN11 mutations, encoding for SHP2, and downstream activation of Ras/MAPK pathway, have been identified in the majority of NS patients [14]. This led to the discovery that somatic PTPN11 mutations are the most common genetic lesions in sporadic JMML accounting for $35 \%$ of all cases $[15,16]$. Functional studies have shown that most of the SHP2 mutations associated with JMML have a stronger gain-of-function effects than those seen in NS, which may explain the transient nature of NS/TMP [17-19]. JMML associated with PTPN11 mutations is uniformly fatal without HSCT.

Somatic point mutations in NRAS or KRAS leading to gainof-function alterations in Ras proteins are identified in up to 20-25\% of JMML cases. Most mutations occur in codons 12 , 13 , or 61 , leading to an active Ras-GTP-bound state and downstream activation [20,21]. JMML associated with NRAS or KRAS mutations is aggressive and requires urgent HSCT.

Germ line or somatic mutations in $C B L$, the gene encoding $\mathrm{CBL}$, an E3-ubiquitin ligase have been identified in nearly $10 \%$ of JMML patients. In addition to myeloproliferative disease, germ line $C B L$ mutations result in additional deformities, including developmental delay and cryptorchidism, a Noonan syndrome-like phenotype. As in NF1, leukemogenesis is initiated by $\mathrm{LOH}$ at the $C B L$ locus [22]. Interestingly, many patients with JMML and germ line $C B L$ mutations show spontaneous regression of their leukemia, but suffer multiorgan vasculitides later in life. HSCT in these patients may be directed more towards immune reconstitution and is not indicated unless they show rapid progression of disease [22]. Patients with somatic mutations in $C B L$ are nonsyndromic and JMML arising in this background tends to have an aggressive clinical course.

Whole exome sequencing has identified mutations in SETBP1 and JAK3 mutations in up to $17 \%$ of JMML patients. However, they appear to be secondary mutations and not initiating events [23]. ASXL1 mutations are identified in a minority of JMML patients but IDH1/2, TET2, EZH2, DNMT3A, SRFS2, U2AF1, and SF3B1 mutations have not been described $[23,24]$.

\section{Revised diagnostic criteria}

The discovery of genetic mutations and cytogenetic alterations associated with JMML have been incorporated into the new recommended diagnostic criteria for JMML [25, 26], which is more specific compared to the existing WHO 2008 [1] criteria (Table 1). Existing diagnostic assays such as GM-CSF hypersensitivity of myeloid precursors involve techniques that are difficult to reproduce and hence are only available in specialized centers. Newer tests like GM-CSF-mediated hyperphosphorylation of STAT5 protein by flow cytometry show promise but are not yet approved for clinical use [27].

\section{Prognostic features}

JMML remains a genetically and phenotypically heterogeneous entity with some patients showing spontaneous regression while others succumb rapidly. Several studies have examined mutational status with phenotypic severity, but results have been varied. One study showed that older age at diagnosis, PTPN11 mutations, and $\mathrm{Hb} \mathrm{F}>10 \%$ were poor prognostic factors [28]. Patients who present with NS/TMP are most likely to show spontaneous regression of their disease, and

Table 1 Revised diagnostic criteria for juvenile myelomonocytic leukemia (adapted from [25] and [26])

\begin{tabular}{|c|c|c|}
\hline $\begin{array}{l}\text { Category } 1 \\
\text { All of the following }\end{array}$ & $\begin{array}{l}\text { Category } 2 \\
\text { At least one of the following }\end{array}$ & $\begin{array}{l}\text { Category } 3 \\
\text { At least two of the following }\end{array}$ \\
\hline - Splenomegaly & - Somatic mutation in $R A S$ or PTPN11 & - Circulating myeloid precursors* \\
\hline - Absolute monocyte count (AMC) $>1000 / \mathrm{mL}^{*}$ & - Clinical diagnosis of $\mathrm{NF} 1$ or $N F 1$ gene mutation & - $\mathrm{WBC}>10,000 / \mathrm{mL}^{*}$ \\
\hline - Blasts in $\mathrm{PB} / \mathrm{BM}<20 \% *$ & • Homozygous mutation in $C B L$ & - Increased fetal hemoglobin (Hgb F) for age* \\
\hline - Absence of the $\mathrm{t}(9 ; 22) B C R-A B L$ fusion gene* & • Monosomy $7^{*}$ & $\begin{array}{l}\text { - Clonal cytogenetic abnormality excluding } \\
\text { monosomy } 7 * \\
\text { - GM-CSF hypersensitivity* }\end{array}$ \\
\hline
\end{tabular}

The diagnosis of JMML is made if a patient meets all of the category 1 criteria and one of the category 2 criteria without needing to meet the category 3 criteria. If there are no category 2 criteria met, then the category 3 criteria must be met

*Current WHO 2008 diagnostic criteria 
the same holds true for the vast majority of patients with germ line $C B L$ mutations. A subset of JMML patients with RAS G12S mutations have shown spontaneous hematologic improvement with minimal or no therapy in one study, leading the authors to suggest that this specific mutation leads to a milder phenotype [29]. However, other groups have demonstrated lack of genotype-phenotype correlation in JMML patients with RAS mutations [30].

Gene expression profiling studies have shown that JMML can be segregated into an AML-like group and a non-AMLlike group, with a significantly poorer survival in the former [31]. For now, poor prognostic factors include older age (>1.4-4 years), increased fetal hemoglobin (hemoglobin $\mathrm{F}$, $>40 \%)$, reduced platelets $(<33,000 / \mu \mathrm{L})$, monosomy 7 , and mutated PTPN11 [32].

\section{Therapy}

HSCT remains the definitive therapy of choice in JMML. However, 5-year overall survival remains suboptimal at $64 \%$. Additional therapeutic options for symptomatic patients include pre-HSCT chemotherapy or splenectomy [26]. Targeted therapies against the RAS/MAPK pathway and epigenetic modulators are currently under clinical trials [8].

\section{Pediatric chronic myelomonocytic leukemia}

Pediatric CMML is a rare MDS/MPN that is considered a therapy-related myeloid neoplasm seen secondary to chemotherapy or radiotherapy. However, it has also been reported in children in their late teenage years without a history of toxic exposure. The incidence of pediatric CMML is unknown. The current diagnostic criteria are: (i) peripheral monocytosis $\left(>1 \times 10^{9} / \mathrm{L}\right)$, (ii) absence of $(9: 22)(B C R-A B L)$ rearrangement, (iii) absence of rearrangement involving PDGFRA, PDGFRB, or FGFR1 genes, (iv) $<20 \%$ blasts in the bone marrow or peripheral blood, (v) prior therapy, (vi) one of the following evidence of dysplasia, acquired cytogenetic abnormality, or unexplained monocytosis for at least 3 months [33]. The prognostic factors and genetic lesions underlying pediatric CMML are not well defined.

\section{Myelodysplastic/myeloproliferative neoplasms, unclassifiable}

This is a rare subset of MDS/MPN, which does not fulfill criteria for the other specific MDS/MPN entities, including CMML, JMML, and aCML, BCR-ABL negative (Fig. 1gi). The WHO 2008 classification also included refractory anemia with ring sideroblasts and thrombocytosis (RARS-T) as a provisional entity within this subgroup. The incidence MDS/
MPN, $U$ in the pediatric population is not well known. In the largest series published to date, the youngest patient was 22 years old [34].

\section{Related disease of undetermined significance}

\section{RAS-associated autoimmune leukoproliferative disorder}

\section{Introduction and epidemiology}

In 2007, Oliviera et al. described a 49-year-old male with a history of "acute leukemia" in infancy which resolved with minimal therapy, followed by a lifelong history of lymphadenopathy, splenomegaly, multiple autoantibodies, leukocytosis with monocytosis and lymphocytosis, and large B cell lymphoma as a young adult. The patient was presumptively diagnosed with a variant of autoimmune lymphoproliferative syndrome (ALPS). Subsequently, genetic analysis showed a heterozygous somatic mutation (originally misreported as germ line) in codon 13 (p. G13D) of NRAS leading to hyperactivation of the $R A S / R A F / E R K$ pathway [35]. Somatic gain-offunction KRAS mutations (p. G13C, G13D, G12D, and G12S) were identified in other patients being evaluated for ALPS with similar clinical features, including peripheral blood monocytosis, reminiscent of juvenile myelomonocytic leukemia [36]. The term "RAS-associated autoimmune leukoproliferative disorder (RALD)" was adopted and incorporated into the ALPS classification to distinguish it from ALPS harboring mutations in FAS, FASL, or CASP10 [37]. RALD is a newly described clinical entity of underdetermined significance, with features overlapping with both JMML and ALPS. The incidence of RALD is currently undefined.

\section{Clinical and laboratory features}

RALD typically presents in childhood, most often within the first 2 years of life (ranging from 3 months to 5 years in one study) [38] and persists throughout adolescence with an indolent clinical course. Persistent relative or absolute peripheral blood monocytosis, B cell lymphocytosis, hypergammaglobulinemia, lymphadenopathy, and splenomegaly have been described in virtually all patients. Auto-antibodies, including anti-nuclear antibodies (ANA), anti-cardiolipin (ACA), and lupus anticoagulant are common [35]. Autoimmune cytopenias are common.

Peripheral blood immunophenotyping has shown increased activated CD16+ monocytes, B cell lymphocytosis with polytypic expression of kappa and lambda light chains, a subset of patients with increased circulating CD10+ late precursor B cells, and CD14 (dim) positive granulocytes [38]. Circulating CD4-/CD8-/TCR $\alpha \beta \mathrm{T}$ cells are not 
typically increased. GM-CSF hypersensitivity of myeloid progenitor cells is positive in a subset of patients. Examination of peripheral blood smear shows monocytosis with predominantly large mature vacuolated monocytes (Fig. 1j).

\section{Histologic features}

Lymph node biopsies have shown non-specific features, including follicular hyperplasia, paracortical expansion, and sinus histiocytosis, including features reminiscent of Rosai-Dorfman disease [39]. Bone marrows are mildly hypercellular with leftshifted myeloid maturation and mild or minimal myeloid dyspoiesis [38] (Fig. 1k-1). Bone marrow cytogenetic analyses have demonstrated a normal karyotype in all RALD patients.

\section{Genetics and biology}

The first documented case of RALD demonstrated a somatic NRAS mutation in codon 13, while subsequent cases have shown somatic mutations in NRAS or $K R A S$, involving codons 12 or 13 in myeloid and lymphoid cells [40]. These mutations impart gain-offunction effects by stabilizing RAS proteins in the active GTP-bound state and reduced expression of a proapoptotic protein, BCL2-interacting mediator of cell death (BIM). Reduced BIM levels have been documented in leukocytes from RALD patients, suggesting that like ALPS, RALD is a disorder of defective apoptosis $[35,36]$.
Table 2 Features of RALD and JMML (modified from [38])

\begin{tabular}{|c|c|c|}
\hline & RALD & JMML \\
\hline \multicolumn{3}{|l|}{ Clinical and laboratory findings } \\
\hline Massive Splenomegaly & Common & Common \\
\hline Rash and arthralgias & Common & Common \\
\hline Autoimmune disorders & Common & Reported in subset \\
\hline Autoantibodies (DAT, ACA, ANA) & Common & Reported in subset \\
\hline Increased $\mathrm{Hb} \mathrm{F}$ for age & Yes in subset & Common \\
\hline $\operatorname{Anemia}(<10 \mathrm{~g} / \mathrm{dL})$ & $10 \%$ & Common \\
\hline Thrombocytopenia $(<100 \mathrm{~K} / \mathrm{uL})$ & $30 \%$ & Common \\
\hline Infiltration of extramedullary tissues by myelomonocytic cells & No & Common \\
\hline Clinical course & Indolent & Aggressive \\
\hline \multicolumn{3}{|l|}{ Peripheral blood flow and morphology } \\
\hline \multicolumn{3}{|l|}{ Monocytes } \\
\hline Monocytosis $(>1.0 \mathrm{~K} / \mathrm{uL})$ & Nearly $100 \%$ & $100 \%$ \\
\hline CD16 expression (activated phenotype) & $82 \%$ & Unreported \\
\hline \multicolumn{3}{|l|}{ Atypical expression of other markers on monocytes } \\
\hline CD56+, CD13-, CD10+ & $18 \%$ & Unreported \\
\hline Circulating immature monos & $23 \%$ & Common \\
\hline Circulating vacuolated monocytes & Common & Variable \\
\hline \multicolumn{3}{|l|}{ Granulocytes and lymphocytes } \\
\hline Neutropenia $(<1.3 \mathrm{~K} / \mathrm{uL})$ & $30 \%$ & Reported in subset \\
\hline Neutrophilia $(>8.0 \mathrm{~K} / \mathrm{uL})$ & $20 \%$ & Reported in subset \\
\hline Atypical CD14+ (dim) expression on granulocytes & $64 \%$ & Unreported \\
\hline Circulating blasts & $0 \%$ & Common \\
\hline Pelgeroid granulocytes & $15 \%$ & Common \\
\hline $\begin{array}{l}\text { B cells, polyclonal B lymphocytosis with circulating late } \\
\text { hematogones (CD19+, CD10+, CD20+) }\end{array}$ & $64 \%$ & Unreported \\
\hline Bone marrow cytogenetic abnormalities & $0 \%$ & $25-35 \%$ \\
\hline Apoptosis defect (IL2 cytokine withdrawal assay) & $100 \%$ & Unknown \\
\hline GM-CSF hypersensitivity assay & Positive in subset & Positive \\
\hline$K R A S$ or $N R A S$ mutations & $100 \%$ & $20-25 \%$ \\
\hline PTPN11 mutations & $0 \%$ & $\sim 35 \%$ \\
\hline NF1 mutations & $0 \%$ & $10-15 \%$ \\
\hline$C B L$ mutations & $0 \%$ & $\sim 10 \%$ \\
\hline
\end{tabular}




\section{Current diagnostic and prognostic criteria}

RALD is rare but should be considered in the differential diagnosis of JMML and ALPS due to overlapping clinical presentation and laboratory features. The absence of circulating CD4-/CD8- TCR $\alpha \beta$ T cells and lack of mutations in FAS, FASLG, or CASP10 need to be confirmed to rule out ALPS [37]. In general, RALD patients are not as acutely ill as patients with JMML. However, distinguishing RALD from JMML on the basis of the 2008 WHO or revised JMML criteria may not be possible in all cases. Occasional patients with fulfilling diagnostic criteria for JMML and with RAS mutations have shown spontaneous resolution of leukocytosis but persistent hepatosplenomegaly, autoimmunity, and RAS clones in their hematopoietic cells, suggestive of RALD [41]. While there are some distinctive features of RALD that help to differentiate it from JMML (Table 2), retrospective studies of JMML patients and long-term follow-up of RALD patients with serial monitoring of hematologic parameters and genetic and cytogenetic markers is required for the development of accurate diagnostic criteria to distinguish these entities.

Current evidence gained from follow-up of small patient cohorts supports an overall indolent clinical course for RALD $[36,38]$. Complications arising from autoimmunity and inflammation may be problematic in some patients. A small subset of RALD patients with KRAS mutations have had pericarditis and/or pericardial effusions with one fatality presumed due to cardiac failure due to inflammation; malignancy was ruled out by autopsy in that patient [38]. However, a recent report documented aggressive transformation of RALD to severe JMML, 10 years after RALD diagnosis, suggesting that these entities are related and lie within a spectrum of severity [39]. Future studies will be directed towards understanding the natural history and evolution of RALD.

\section{Therapy}

Current treatment for RALD is aimed towards alleviation of symptoms using immunosuppressive medications like sirolimus. A small number of patients have undergone splenectomy to obtain relief from pain and discomfort associated hypersplenism. Close clinical and laboratory monitoring of RALD patients for acquisition of dysplastic or karyotypic abnormalities that may herald malignant transformation is recommended.

\section{Conclusions}

Rapid advances have been made in the diagnosis and management of JMML. New diagnostic guidelines with the incorporation of mutation analysis have allowed for more accurate and early diagnosis and detection of minimal disease. Although JMML remains an aggressive disease with high therapy-related morbidity and mortality, targeted therapies aimed at the RAS/MAPK pathway offer exciting avenues for disease control.

The identification of RALD as a unique clinical entity with a less aggressive clinical course but sharing RAS aberrations with JMML will allow us to study the natural course of these proliferations and identify significant secondary alterations that affect disease progression and overall disease prognosis.

Funding The Intramural Research Program of the National Institutes of Health of the USA supported this work.

Compliance with Ethical Standards All procedures performed involving human participants were in accordance with the ethical standards of the institutional and/or national research committee and with the 1964 Helsinki declaration and its later amendments or comparable ethical standards. Images of diagnostic peripheral blood, bone marrow, or spleen specimens were taken from clinical samples for which informed consent was obtained prior to procedure.

Conflicts of interest The authors declare that they have no conflict of interest.

\section{References}

1. Swerdlow SH, Campo E, Harris NL, Jaffe ES, Pileri SA, Stein H, Thiele J, Vardiman JW (2008) WHO classification of tumours of haematopoietic and lymphoid tissues. International Agency for Research on Cancer, Lyon

2. Niemeyer CM (2014) RAS diseases in children. Haematologica 99(11):1653-1662. doi:10.3324/haematol.2014.114595

3. Zoi K, Cross NC (2015) Molecular pathogenesis of atypical CML, CMML and MDS/MPN-unclassifiable. Int J Hematol 101(3):229 242. doi:10.1007/s12185-014-1670-3

4. Niemeyer CM, Arico M, Basso G, Biondi A, Cantu Rajnoldi A, Creutzig U, Haas O, Harbott J, Hasle H, Kerndrup G, Locatelli F, Mann G, Stollmann-Gibbels B, van't Veer-Korthof ET, van Wering E, Zimmermann M (1997) Chronic myelomonocytic leukemia in childhood: a retrospective analysis of 110 cases. European Working Group on Myelodysplastic Syndromes in Childhood (EWOGMDS). Blood 89(10):3534-3543

5. Luna-Fineman S, Shannon KM, Atwater SK, Davis J, Masterson M, Ortega J, Sanders J, Steinherz P, Weinberg V, Lange BJ (1999) Myelodysplastic and myeloproliferative disorders of childhood: a study of 167 patients. Blood 93(2):459-466

6. Emanuel PD, Bates LJ, Castleberry RP, Gualtieri RJ, Zuckerman KS (1991) Selective hypersensitivity to granulocyte-macrophage colony-stimulating factor by juvenile chronic myeloid leukemia hematopoietic progenitors. Blood 77(5):925-929

7. Proytcheva M (2011) Juvenile myelomonocytic leukemia. Semin Diagn Pathol 28(4):298-303

8. Chang TY, Dvorak CC, Loh ML (2014) Bedside to bench in juvenile myelomonocytic leukemia: insights into leukemogenesis from a rare pediatric leukemia. Blood 124(16):2487-2497. doi:10.1182/ blood-2014-03-300319 
9. Side L, Taylor B, Cayouette M, Conner E, Thompson P, Luce M, Shannon K (1997) Homozygous inactivation of the NF1 gene in bone marrow cells from children with neurofibromatosis type 1 and malignant myeloid disorders. N Engl J Med 336(24):1713-1720. doi:10.1056/NEJM199706123362404

10. Steinemann D, Arning L, Praulich I, Stuhrmann M, Hasle H, Stary J, Schlegelberger B, Niemeyer CM, Flotho C (2010) Mitotic recombination and compound-heterozygous mutations are predominant NF1-inactivating mechanisms in children with juvenile myelomonocytic leukemia and neurofibromatosis type 1 . Haematologica 95(2):320-323

11. Bader-Meunier B, Tchernia G, Mielot F, Fontaine JL, Thomas C, Lyonnet S, Lavergne JM, Dommergues JP (1997) Occurrence of myeloproliferative disorder in patients with Noonan syndrome. $\mathrm{J}$ Pediatr 130(6):885-889

12. Side LE, Shannon KM (1997) Myeloid disorders in infants with Noonan syndrome and a resident's "rule" recalled. J Pediatr 130(6): 857-859

13. Choong K, Freedman MH, Chitayat D, Kelly EN, Taylor G, Zipursky A (1999) Juvenile myelomonocytic leukemia and Noonan syndrome. J Pediatr Hematol Oncol 21(6):523-527

14. Tartaglia M, Kalidas K, Shaw A, Song X, Musat DL, van der Burgt I, Brunner HG, Bertola DR, Crosby A, Ion A, Kucherlapati RS, Jeffery S, Patton MA, Gelb BD (2002) PTPN11 mutations in Noonan syndrome: molecular spectrum, genotype-phenotype correlation, and phenotypic heterogeneity. Am J Hum Genet 70(6): $1555-1563$

15. Tartaglia M, Niemeyer CM, Fragale A, Song X, Buechner J, Jung A, Hahlen K, Hasle H, Licht JD, Gelb BD (2003) Somatic mutations in PTPN11 in juvenile myelomonocytic leukemia, myelodysplastic syndromes and acute myeloid leukemia. Nat Genet 34(2):148-150

16. Loh ML, Vattikuti S, Schubbert S, Reynolds MG, Carlson E, Lieuw KH, Cheng JW, Lee CM, Stokoe D, Bonifas JM, Curtiss NP, Gotlib J, Meshinchi S, Le Beau MM, Emanuel PD, Shannon KM (2004) Mutations in PTPN11 implicate the SHP-2 phosphatase in leukemogenesis. Blood 103(6):2325-2331

17. Araki T, Mohi MG, Ismat FA, Bronson RT, Williams IR, Kutok JL, Yang W, Pao LI, Gilliland DG, Epstein JA, Neel BG (2004) Mouse model of Noonan syndrome reveals cell type- and gene dosagedependent effects of Ptpn11 mutation. Nat Med 10(8):849-857

18. Mohi MG, Williams IR, Dearolf CR, Chan G, Kutok JL, Cohen S, Morgan K, Boulton C, Shigematsu H, Keilhack H, Akashi K, Gilliland DG, Neel BG (2005) Prognostic, therapeutic, and mechanistic implications of a mouse model of leukemia evoked by Shp2 (PTPN11) mutations. Cancer Cell 7(2):179-191

19. Kratz CP, Niemeyer CM, Castleberry RP, Cetin M, Bergstrasser E, Emanuel PD, Hasle H, Kardos G, Klein C, Kojima S, Stary J, Trebo M, Zecca M, Gelb BD, Tartaglia M, Loh ML (2005) The mutational spectrum of PTPN11 in juvenile myelomonocytic leukemia and Noonan syndrome/myeloproliferative disease. Blood 106(6): 2183-2185. doi:10.1182/blood-2005-02-0531

20. Miyauchi J, Asada M, Sasaki M, Tsunematsu Y, Kojima S, Mizutani S (1994) Mutations of the N-ras gene in juvenile chronic myelogenous leukemia. Blood 83(8):2248-2254

21. Flotho C, Valcamonica S, Mach-Pascual S, Schmahl G, Corral L, Ritterbach J, Hasle H, Arico M, Biondi A, Niemeyer CM (1999) RAS mutations and clonality analysis in children with juvenile myelomonocytic leukemia (JMML). Leukemia 13(1):32-37

22. Niemeyer CM, Kang MW, Shin DH, Furlan I, Erlacher M, Bunin NJ, Bunda S, Finklestein JZ, Sakamoto KM, Gorr TA, Mehta P, Schmid I, Kropshofer G, Corbacioglu S, Lang PJ, Klein C, Schlegel P-G, Heinzmann A, Schneider M, Stary J, van den Heuvel-Eibrink MM, Hasle H, Locatelli F, Sakai D, Archambeault S, Chen L, Russell RC, Sybingco SS, Ohh M, Braun BS, Flotho C, Loh ML (2010) Germline CBL mutations cause developmental abnormalities and predispose to juvenile myelomonocytic leukemia. Nat Genet 42(9):794-800

23. Sakaguchi H, Okuno Y, Muramatsu H, Yoshida K, Shiraishi Y, Takahashi M, Kon A, Sanada M, Chiba K, Tanaka H, Makishima H, Wang X, Xu Y, Doisaki S, Hama A, Nakanishi K, Takahashi Y, Yoshida N, Maciejewski JP, Miyano S, Ogawa S, Kojima S (2013) Exome sequencing identifies secondary mutations of SETBP1 and JAK3 in juvenile myelomonocytic leukemia. Nat Genet 45(8):937941. doi:10.1038/ng.2698

24. Sugimoto Y, Muramatsu H, Makishima H, Prince C, Jankowska AM, Yoshida N, Xu Y, Nishio N, Hama A, Yagasaki H, Takahashi Y, Kato K, Manabe A, Kojima S, Maciejewski JP (2010) Spectrum of molecular defects in juvenile myelomonocytic leukaemia includes ASXL1 mutations. Br J Haematol 150(1):83-87

25. Chan RJ, Cooper T, Kratz CP, Weiss B, Loh ML (2009) Juvenile myelomonocytic leukemia: a report from the 2nd International JMML Symposium. Leuk Res 33(3):355-362. doi:10.1016/j. leukres.2008.08.022

26. Dvorak CC, Loh ML (2014) Juvenile myelomonocytic leukemia: molecular pathogenesis informs current approaches to therapy and hematopoietic cell transplantation. Front Pediatr 2:25. doi:10.3389/ fped.2014.00025

27. Hasegawa D, Bugarin C, Giordan M, Bresolin S, Longoni D, Micalizzi C, Ramenghi U, Bertaina A, Basso G, Locatelli F, Biondi A, Te Kronnie G, Gaipa G (2013) Validation of flow cytometric phospho-STAT5 as a diagnostic tool for juvenile myelomonocytic leukemia. Blood Cancer J 3:e160. doi:10.1038/ bcj.2013.56

28. Yoshida N, Yagasaki H, Xu Y, Matsuda K, Yoshimi A, Takahashi Y, Hama A, Nishio N, Muramatsu H, Watanabe N, Matsumoto K, Kato K, Ueyama J, Inada H, Goto H, Yabe M, Kudo K, Mimaya J, Kikuchi A, Manabe A, Koike K, Kojima S (2009) Correlation of clinical features with the mutational status of GM-CSF signaling pathway-related genes in juvenile myelomonocytic leukemia. Pediatr Res 65(3):334-340. doi:10.1203/PDR.0b013e3181961d2a

29. Matsuda K, Shimada A, Yoshida N, Ogawa A, Watanabe A, Yajima S, Iizuka S, Koike K, Yanai F, Kawasaki K, Yanagimachi M, Kikuchi A, Ohtsuka Y, Hidaka E, Yamauchi K, Tanaka M, Yanagisawa R, Nakazawa Y, Shiohara M, Manabe A, Kojima S, Koike K (2007) Spontaneous improvement of hematologic abnormalities in patients having juvenile myelomonocytic leukemia with specific RAS mutations. Blood 109(12):5477-5480. doi:10.1182/ blood-2006-09-046649

30. Flotho C, Kratz CP, Bergstrasser E, Hasle H, Stary J, Trebo M, van den Heuvel-Eibrink MM, Wojcik D, Zecca M, Locatelli F, Niemeyer CM, European Working Group of Myelodysplastic Syndromes in C (2008) Genotype-phenotype correlation in cases of juvenile myelomonocytic leukemia with clonal RAS mutations. Blood 111(2):966-967. doi:10.1182/blood-2007-09-111831

31. Bresolin S, Zecca M, Flotho C, Trentin L, Zangrando A, Sainati L, Stary J, de Moerloose B, Hasle H, Niemeyer CM, Te Kronnie G, Locatelli F, Basso G (2010) Gene expression-based classification as an independent predictor of clinical outcome in juvenile myelomonocytic leukemia. J Clin Oncol 28(11):1919-1927

32. Locatelli F, Crotta A, Ruggeri A, Eapen M, Wagner JE, Macmillan ML, Zecca M, Kurtzberg J, Bonfim C, Vora A, Diaz de Heredia C, Teague L, Stein J, O'Brien TA, Bittencourt H, Madureira A, Strahm B, Peters C, Niemeyer C, Gluckman E, Rocha V (2013) Analysis of risk factors influencing outcomes after cord blood transplantation in children with juvenile myelomonocytic leukemia: a EUROCORD, EBMT, EWOG-MDS, CIBMTR study. Blood 122(12):2135-2141. doi:10.1182/blood-2013-03-491589

33. Hasle H, Niemeyer CM, Chessells JM, Baumann I, Bennett JM, Kerndrup G, Head DR (2003) A pediatric approach to the WHO 
classification of myelodysplastic and myeloproliferative diseases. Leukemia 17(2):277-282. doi:10.1038/sj.leu.2402765

34. DiNardo CD, Daver N, Jain N, Pemmaraju N, Bueso-Ramos C, Yin CC, Pierce S, Jabbour E, Cortes JE, Kantarjian HM, Garcia-Manero G, Verstovsek S (2014) Myelodysplastic/myeloproliferative neoplasms, unclassifiable (MDS/MPN, U): natural history and clinical outcome by treatment strategy. Leukemia 28(4):958-961. doi:10. 1038/leu.2014.8

35. Oliveira JB, Bidere N, Niemela JE, Zheng L, Sakai K, Nix CP, Danner RL, Barb J, Munson PJ, Puck JM, Dale J, Straus SE, Fleisher TA, Lenardo MJ (2007) NRAS mutation causes a human autoimmune lymphoproliferative syndrome. Proc Natl Acad Sci U S A 104(21):8953-8958. doi:10.1073/pnas.0702975104

36. Takagi M, Shinoda K, Piao J, Mitsuiki N, Takagi M, Matsuda K, Muramatsu H, Doisaki S, Nagasawa M, Morio T, Kasahara Y, Koike K, Kojima S, Takao A, Mizutani S (2011) Autoimmune lymphoproliferative syndrome-like disease with somatic KRAS mutation. Blood 117(10):2887-2890. doi:10.1182/blood-2010-08301515

37. Oliveira JB, Bleesing JJ, Dianzani U, Fleisher TA, Jaffe ES, Lenardo MJ, Rieux-Laucat F, Siegel RM, Su HC, Teachey DT, Rao VK (2010) Revised diagnostic criteria and classification for the autoimmune lymphoproliferative syndrome (ALPS): report from the 2009 NIH International Workshop. Blood 116(14):e35e40. doi:10.1182/blood-2010-04-280347

38. Calvo KR, Price S, Braylan RC, Oliveira JB, Lenardo M, Fleisher TA, Rao VK (2015) JMML and RALD (Ras-associated autoimmune leukoproliferative disorder): common genetic etiology yet clinically distinct entities. Blood 125(18):2753-2758. doi:10. 1182/blood-2014-11-567917

39. Lanzarotti N, Bruneau J, Trinquand A, Stolzenberg MC, Neven B, Fregeac J, Levy E, Jeremiah N, Suarez F, Mahlaoui N, Fischer A, Magerus-Chatinet A, Cave H, Rieux-Laucat F (2014) RASassociated lymphoproliferative disease evolves into severe juvenile myelo-monocytic leukemia. Blood 123(12):1960-1963. doi:10. 1182/blood-2014-01-548958

40. Niemela JE, Lu L, Fleisher TA, Davis J, Caminha I, Natter M, Beer LA, Dowdell KC, Pittaluga S, Raffeld M, Rao VK, Oliveira JB (2011) Somatic KRAS mutations associated with a human nonmalignant syndrome of autoimmunity and abnormal leukocyte homeostasis. Blood 117(10):2883-2886. doi:10.1182/blood-2010-07295501

41. Takagi M, Piao J, Lin L, Kawaguchi H, Imai C, Ogawa A, Watanabe A, Akiyama K, Kobayashi C, Mori M, Ko K, Sugimoto M, Mizutani S (2013) Autoimmunity and persistent RAS-mutated clones long after the spontaneous regression of JMML. Leukemia 27(9):1926-1928. doi:10.1038/leu.2013.82 